\title{
Rural space and rural social enterprise
}

\author{
Presentation by Scott \\ Rural Symposium 2017
}

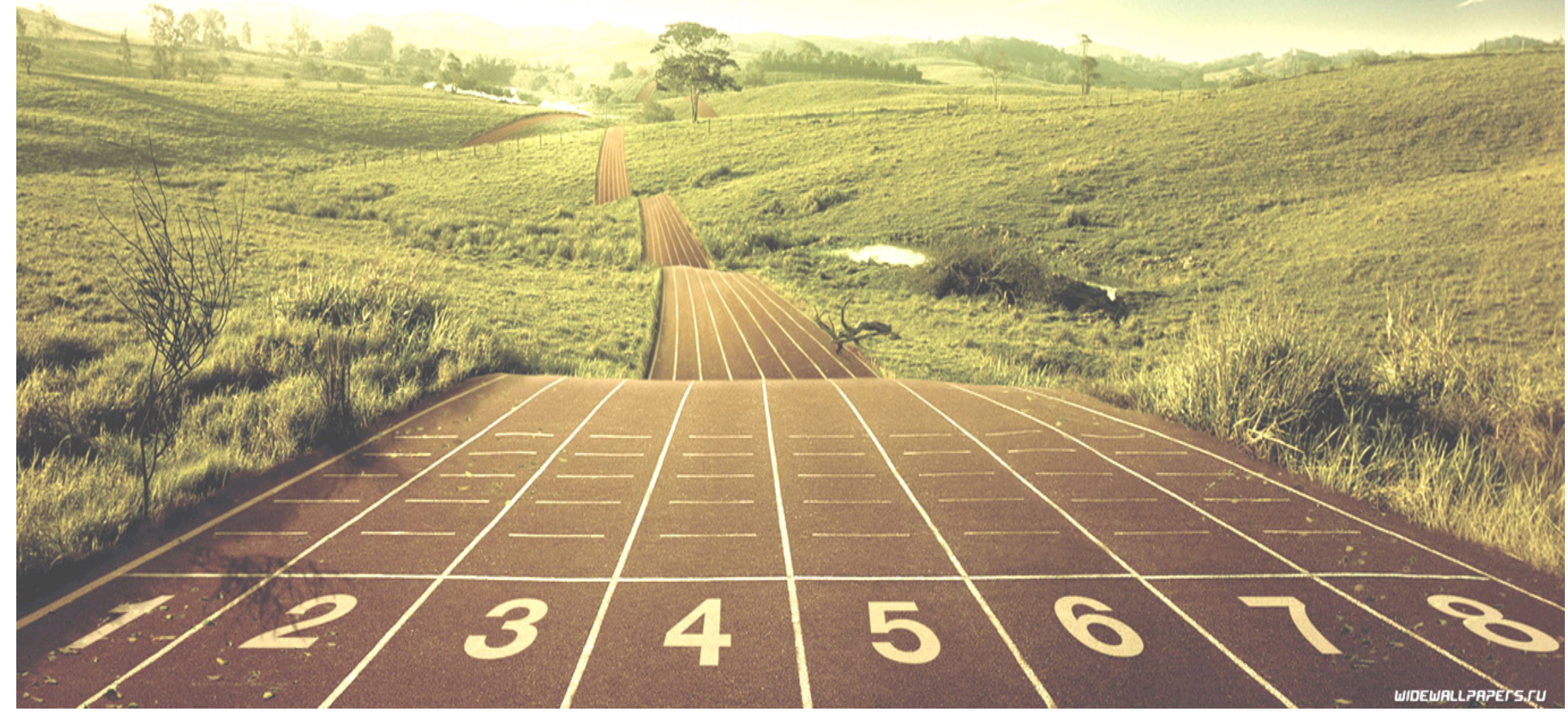




\section{Contents:}

1) Foundations of the Research

(spatial turn, Lefebvre, Halfacree)

2) Research Focus

(rural space and the 'spaces of social enterprise')

3) General Implications

(rural policy, opportunities, etc.) 
"Prophesy now involves a geographical rather than historical projection; it is space not time that hides consequences from us". (Soja, 1987, p. 22)

"It is precisely the critical and potentially emancipatory value of the historical imagination, of people "making history' rather than taking it for granted, that had made it so compulsively appealing. The constant reaffirmation that the world can be changed by human action, by praxis, has always been the centrepiece of critical social theory whatever its particularized source and emphasis". (Soja, 1987 , p. 14)

\section{PASYIIODDRBII MWOGBRIPIIIRS}

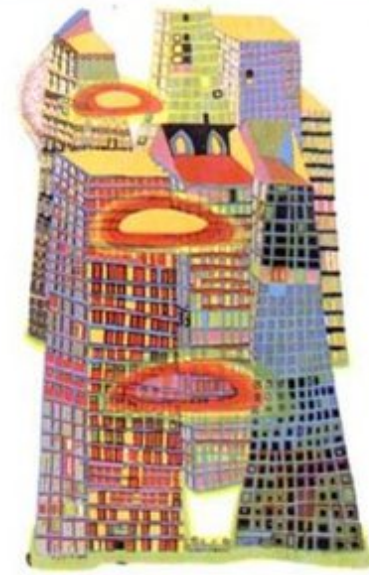

Edward W. Soja
REASSERTION

OF SPACE IN

CRITICAL

SOCIAL

THEORY 
The overarching thesis in his aptly-titled book The Production of Space is that space is in fact produced-a view that contrasts markedly with the idea that space is simply an abstract and empty container waiting to be filled -a "passive receptacle". (Lefebvre, 1974/1991, p. 90)

"[...] we fall into the trap of treating space as space "in itself", as space as such". (Lefebvre, 1974/1991, p. 90)

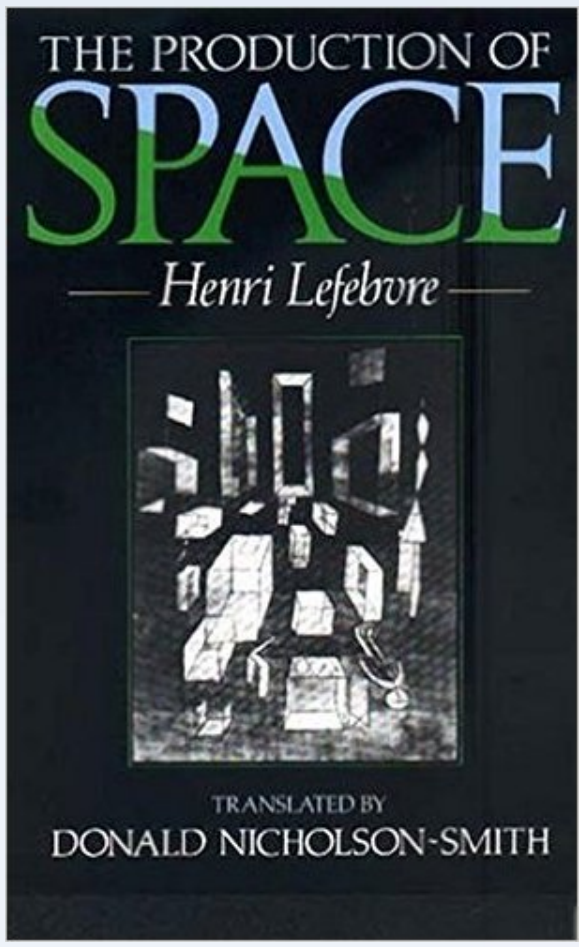

Lefebvre's three facets of space as a way to "interrogate space":

$\rightarrow$ Spatial Practices

$\rightarrow$ Representations of Space

$\rightarrow$ Spaces of Representation (Everyday Lives) 
Halfacree (2006) brought Lefebvre' s spatial triad into the rural realm:

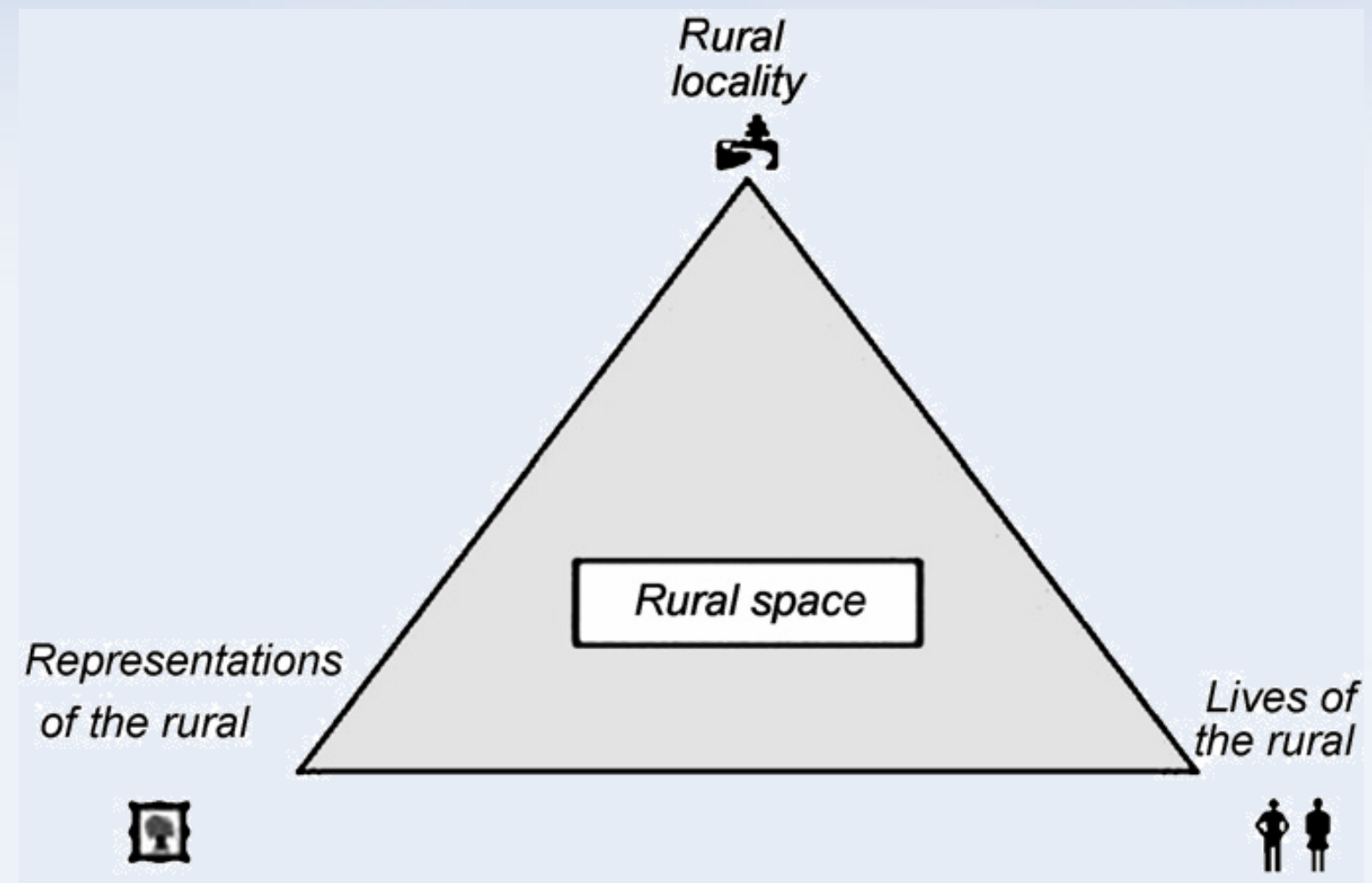

\section{Rural Coherency:}

Congruent and Unified Contradictory and Disjointed Chaotic and Incoherent 
My Research: The Spaces of Rural Social Enterprise

My research is all about using spatial concepts and an explicit focus on space and place to conceptualize rural social enterprise as an integrative activity.

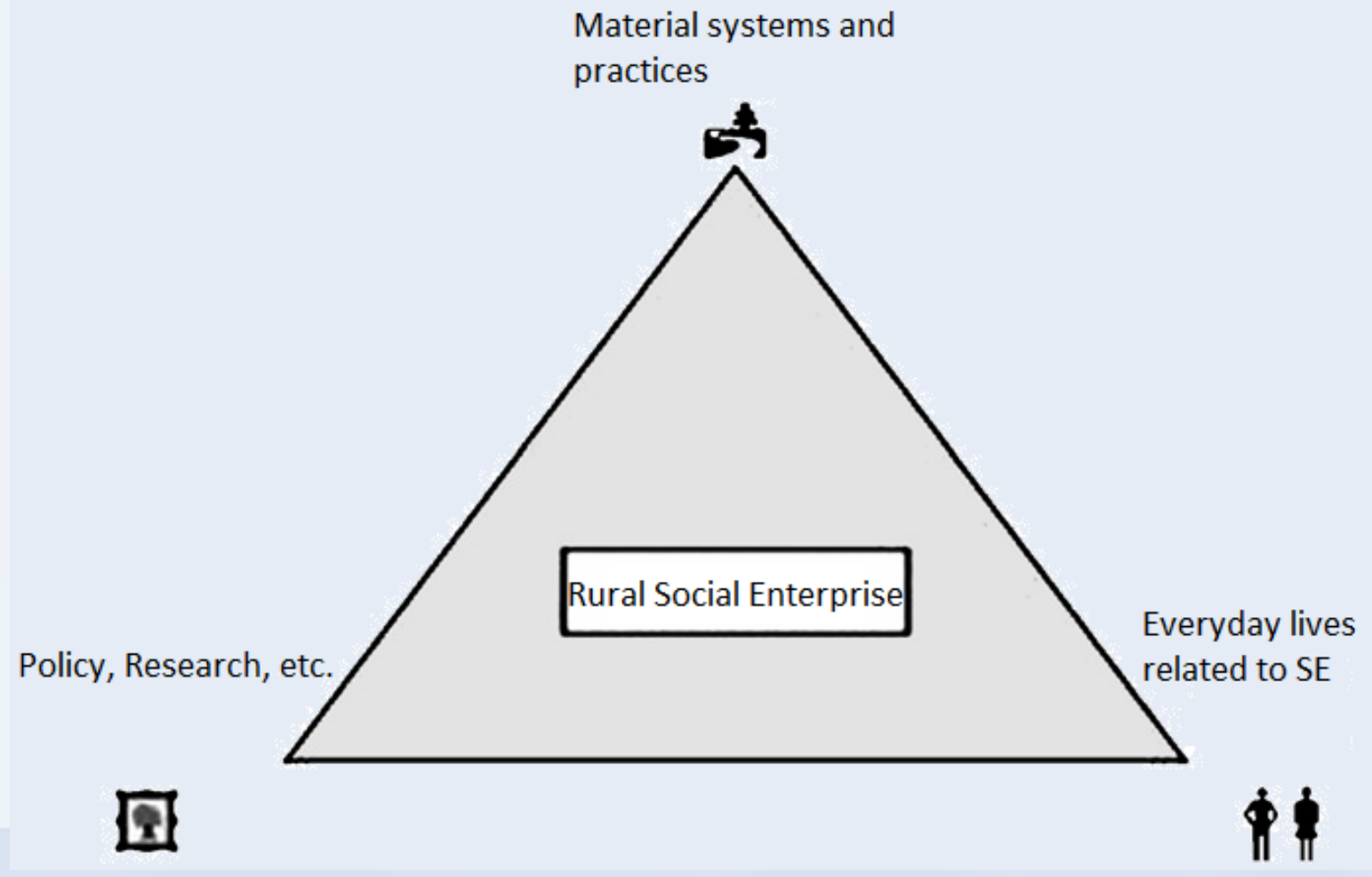


What does this kind of research engagement mean in a broader context?

What are the implications for rural Ontario?

What are the key points of information someone should take away from your presentation? 


\section{Thank you!}

\section{Questions?}

References:

Soja, E. W. (1989). Postmodern geographies. London, UK: Verso.

Lefebvre, H. (1991). The production of space (D. Nicholson-Smith, Trans.). Oxford, UK: Blackwell. (Original work published 1974).

Halfacree, K. (2006). Rural space: Constructing a three-fold architecture. In P. Cloke, T. Marsden, \& P. Mooney (Eds.), The handbook of rural studies (pp. 44-62). London, UK: SAGE. 